\title{
Servikal patoloji şüphesi ile merkezimize refere edilen hastaların değerlendirilmesi ve yönetimi
}

\section{Evaluation and management of patients referred to our center with suspicion of cervical pathology}

\author{
Recep Erin*回, Kübra Baki Erin $\square$, Deniz Kulaksız $\square$, Yeşim Bayoğlu Tekin $\square$, Hatice Küçük $\square$
}

Sağlık Bilimleri Üniversitesi, Trabzon Kanuni Sağlık Uygulama ve Araştırma Hastanesi, Kadın Hastalıkları ve Doğum Bölümü, Trabzon

\section{Öz}

Amaç: Bölgemizdeki Insan Papilloma Virüs (HPV) pozitiflik prevalansını belirlemek ve HPV pozitif olguların tip dağılımını ve yönetimini incelemektir.

Gereç ve Yöntem: Servikal patoloji şüphesi ile ileri tetkik ve inceleme için Ocak 2018 - Aralık 2019 tarihleri arasında Sağlık Bilimleri Üniversitesi Trabzon Kanuni Sağlık Uygulama ve Araştırma Merkezi'ne başvuran hastalar retrospektif olarak incelendi. Hastaların demografik verileri belirlendi. Hastalarda saptanan HPV tiplendirilmesi ve smear sonuçları kaydedildi. Yüksek riskli HPV tipi gözlenen ve kolposkopi yapılan hastaların biyopsi sonuçları değerlendirildi. Çalışma verileri tanımlayııı istatistiki metodlar kullanılarak analiz edildi.

Bulgular: Çalışmaya HPV testi yapılan 6186 hasta dahil edildi. Hastaların yaş ortalaması $43,87 \pm 7,1$ yıl, vücut kitle indeksi 27,1 \pm $6,56 \mathrm{~kg} / \mathrm{m2}$, gravidası 3,4 $\pm 0,43$ idi. Sigara kullanım oranı $\% 22,8$, HPV pozitifliği $\% 5,45$ ( $n=337 / 6186$ ) olarak saptandı. Hastaların servikal smear sonuçlarının dağılımı; normal \%54,3 ( $n=183$ ), enfeksiyon \%19,29 ( $n=65)$, ASC-US \%5,64 ( $n=19)$, LGSIL \%2,37 $(n=8)$, AGC \%0,30 ( $n=1)$ olarak tespit edildi. HPV tiplendirmesinde en sık görülen tipler 91 hastada HPV 16 (\%27), 45 hastada HPV 31 (\%13,4), 43 hastada HPV 51 (\%12,8), 43 hastada HPV 52 (\%12,8) şeklinde idi. Kolposkopik biyopsi sonuçlarında \%49,6 ( $n=167$ ) servikal intraepitelyal neoplazi (CIN) 1,\%7,4 (n=25) CIN 2-3, \%1,2 ( $n=4)$ skuamöz hücreli karsinom tespit edildi.

Sonuç: Çalışmamız sonuçları dahilinde cinsel aktif kadınlarda servikal kanser taramasının önemi bir kere daha ortaya konmuştur. 30 yaş üzerinde HPV DNA ve servikal smear kombinasyonu ile yapılan serviks kanseri tarama programlarına katılmanın önemi akılda tutulmalıdır. Çalışmamız Doğu Karadeniz Bölgesi'nin HPV prevalansını kesitsel olarak göstermesi açısından bir ilktir.

Anahtar kelimeler: Human Papilloma Virüs; servikal smear; servikal intraepitelyal lezyon; kolposkopi; serviks kanseri; Doğu Karadeniz

Sorumlu Yazar*: Recep Erin, Sağlık Bilimleri Üniversitesi, Trabzon Kanuni Sağlık Uygulama ve Araştırma Hastanesi, Trabzon 


\section{Abstract}

Aim: To determine the prevalence of Human Papilloma Virus (HPV) positivity in our region and to examine the type distribution and management of HPV positive cases.

Material and method: Patients who applied to the University of Health Sciences, Trabzon Kanuni Health Practice and Research Center between January 2018 and December 2019 for further examination and examination with suspicion of cervical pathology were retrospectively analyzed. Demographic data of the patients were determined. HPV typing and smear results detected in the patients were recorded. Biopsy and colposcopy results of patients with high-risk HPV types were evaluated. Study data were analyzed using descriptive statistical methods.

Results: 6,186 patients who were tested for HPV were included in the study. The mean age, body mass index and gravida of the patients were $43.87 \pm 7.1$ years, $27.1 \pm 6.56 \mathrm{~kg} / \mathrm{m} 2$, and $3.4 \pm 0.43$, respectively. Smoking rate was $22.8 \%$ and HPV positivity was $5.45 \%(n=337 / 6186)$. Distribution of patients' cervical smear results were determined as normal $54.3 \%$ ( $n$ $=183$ ), infection 19.29\% ( $n=65)$, ASC-US 5.64\% $(n=19)$, LGSIL 2.37\% $(n=8)$ and AGC\% $0.30(n=1)$. The most common types in HPV typing were HPV 16 in 91 patients (27\%), HPV 31 in 45 patients (13.4\%), HPV 51 in 43 patients (12.8\%), HPV 52 in 43 patients $(12.8 \%)$ In colposcopic biopsy results, 49.6\% ( $n=167)$ cervical intraepithelial neoplasia $(\mathrm{CIN}) 1,7.4 \%(n$ $=25) \mathrm{CIN} 2-3,1.2 \%(n=4)$ squamous cell carcinoma cases were detected.

Conclusion: Within the results of our study, the importance of cervical cancer screening in sexually active women has been demonstrated once again. The importance of participating in cervical cancer screening programs performed with the combination of HPV DNA and cervical smear should be kept in mind. To our knowledge, our study is the first to show the HPV prevalence of the Eastern Black Sea Region in cross-section.

Key words: Human Papilloma Virus; cervical smear; cervical intraepithelial lesion; colposcopy; cervical cancer; Eastern Black Sea

\section{Giriş}

İnsan papilloma virüsü (HPV) zarfsız, çift sarmallı dairesel DNA içeren bir virüstür. HPV, dünya çapında en yaygın cinsel yolla bulaşan enfeksiyondur. Amerika Birleşik Devletleri'nde 80 milyona yakın insan şu anda HPV ile enfektedir ve her yıl 14 milyon yeni enfeksiyon görülmektedir (1). Anogenital siğiller, HPV enfeksiyonunun yaygın bir klinik belirtisidir. Yüksek riskli HPV ile kalıcı enfeksiyon, karsinom gelişimi için en önemli bir risk faktörüdür (2). 1999 yılında, Uluslararası Kanser Araştırma Ajansı, 22 ülkenin katıldığı büyük ölçekli bir epidemiyolojik çalışma yapmıştır. HPV, serviks kanseri olan hastaların \%99,7'sinde tanımlanmıştır (3). Servikal intraepitelyal neoplazi (CIN), rahim ağzı kanserine giden süreçte preinvaziv bir lezyondur. Kalıcı HPV enfeksiyonu, CIN'in servikal kansere ilerleme riskini önemli ölçüde artırabilir (2). Servikal kanser dünyada etiyolojisi net olarak bilinen tek jinekolojik kanser haline gelmiştir. Şimdiye kadar 100'den fazla HPV türü tanımlanmıştır. HPV, düşük riskli ve yüksek riskli olarak iki kategoriye ayrılır. Kadınların \%80'i yaşamları boyunca HPV ile karşılaşma riski taşımaktadır. Bulaş oldu ve enfeksiyon gelişti ise enfeksiyonun iki yıl içerisinde yaklaşık \%90 oranında spontan regresyona uğrayacağı bilinmelidir (4).
Türkiye'de HPV DNA pozitifliğini \%28,8-37,2 olarak bildiren çalışmalar vardır. En sık görülen ve yüksek malignite riski taşıyan tipler dünyada ve ülkemizde HPV 16 ve $18^{\prime}$ dir. Ancak diğer yüksek riskli tiplerin de sıklığının arttığı rapor edilmiştir $(5,6)$. HPV prevalansı farklı coğrafi bölge ve ırklara göre değişiklik göstermektedir. Hastanemiz Doğu Karadeniz Bölgesi'nde referans bir merkez olma özelliğini taşımaktadır ve bölgedeki tüm servikal şüpheli lezyonu olan, HPV pozitifliği ya da servikal premalign lezyonu bulunan hastalar ileri inceleme için hastanemize yönlendirilmektedir. Literatürde bölgemizin HPV prevalansı ile ilgili bir veri bulunmamaktadır. Mevcut çalışmada bölgemizdeki HPV pozitiflik prevalansının belirlenmesi ve HPV pozitif olguların tip dağılımının ve yönetiminin incelenmesi amaçlanmıştır.

\section{Gereç ve Yöntem}

Çalışmaya, yerel etik kurul onayı alındıktan sonra (2019/29) Ocak 2018 - Aralık 2019 yılları arasında Sağlık Bilimleri Üniversitesi, Trabzon Kanuni Sağlık Uygulama ve Araştırma Merkezi'ne (SUAM) ileri inceleme için yönlendirilen 6186 hasta dahil edildi. Dosya bilgilerinde eksik bulunan hastalar çalışma dışında tutuldu. Hasta dosyaları retrospektif taranarak hastaların yaş, gravida, parite, vücut kitle indeksi (VKI), sigara alışkanlığı ve özgeçmiş verileri kayıt edildi. 
Kliniğimiz protokolü gereğince servikal patoloji şüphesi ile gelen hastalarda sevikal PAP smear testi yapılmakta sonrasında HPV test kiti olarak Digene ${ }^{\circledR}$ HC2 DNA Collection Device (Qiagen, Germantown, USA) kiti kullanılarak servikal örnekler incelenmektedir. HPV pozitif olan örneklere EZ1 ileri izolasyon cihazı ve virus mini kit (Qiagen, Germantown, USA) kullanılarak PCR uygulanmakta ve Clart HP2 PCR kit (Genomica, Madrid, Spain) ile tiplendirme yapılmaktadır. Hastaların PAP smear sonucunda servikal displazi saptanması ve/veya örneklerde yüksek riskli HPV tipi belirlenmesi durumunda hastalara kolposkopik inceleme yapılmakta ve gerekirse servikal biyopsi alınmaktadır. Anlatılan klinik protokolümüz dahilinde yapılan tetkikler neticesinde elde edilen HPV tiplendirilmesi ve servikal smear sonuçları kaydedildi. Yüksek riskli HPV tipi gözlenen ve kolposkopi yapılan hastaların biyopsi sonuçları değerlendirildi.

\section{İstatistik}

Veriler SPSS 23.0 (Statistical Package for Social Sciences, SPSS Inc., Chicago, IL) paket programı kullanılarak analiz edildi. Çalışma verileri değerlendirilirken tanımlayıcı istatistiksel metodlar (ortalama, standart sapma, ortanca ve frekans) kullanıldı. Sigara içen ve içmeyen hastaların HPV pozitifliğinin kıyaslanmasında Kikare testi yapıldı. $\mathrm{p}<0.05$ anlamlı olarak kabul edildi.

\section{Bulgular}

Hastaların $(n=6186)$ demografik verilerinin analizinde; yaş ortalaması 43,87 $\pm 7,1$ yıl, VKi $27,1 \pm 6,56 \mathrm{~kg} / \mathrm{m} 2$, gravida $3,4 \pm$ 0,43 , parite 2,5 $\pm 0,43$ idi. Hastaların \%22,8 sigara kullanmakta idi. Yapılan HPV testlerinde HPV pozitiflik oranı \%5,45 ( $n=337 / 6186$ ) olarak saptandı. HPV pozitifliğinin yıllara göre dağılımı ise 2018 yılı \%4,91 ( $n=97 / 1975)$ iken 2019 yılı \%5,70 ( $n=240 / 4211$ ) idi (Tablo 1). HPV tiplendirmesinde görülen tipler; HPV $16 \% 27$ ( $n=91)$, HPV $31 \% 13,4(n=45)$, HPV $51 \% 12,8(n=43)$, HPV $52 \% 12,8(n=43)$, HPV $39 \% 9,79(n=33)$, HPV $56 \% 9,50(n=32)$, HPV $68 \% 8,9$ $(n=30)$, HPV $58 \% 6,83(n=23)$, HPV $59 \% 5,93(n=20)$, HPV 35 $\% 5,64$ ( $n=19)$, HPV $18 \% 4,45$ ( $n=15)$, HPV $33 \% 3,86$ ( $n=13)$, HPV $45 \% 3,56(n=12)$ idi (Tablo 2). Kitin sınıflandıramadığı diğer grup HPV tipleri \%28,7 oranında rapor edildi. \%55,8 vakada $\geq 2$ tip \%44,2 vakada tek tip HPV izole edildi. Kolposkopik biyopsi sonuçlarında \%49,6 ( $n=167)$ servikal intraepitelyal neoplazi (CIN) 1, \%7,4 ( $n=25)$ CIN 2-3, \%1,2 ( $n=4)$ skuamöz hücreli karsinom tespit edildi. Kolposkopik biyopsi sonucu CIN 1 saptanan hastalarda en sık HPV 16/31/35/52/56 ve mikst tipler izlendi. CIN 2-3 ise sadece mikst tiplerde görüldü $(n=4)$ (Tablo 3). Sigara içenlerde en sık görülen HPV tipleri 16/31/35/52 iken içmeyenlerde ise 16/31/52/51 idi. Sigara içen ve içmeyenler arasında HPV pozitifliği açısından (\%5,96 vs. \%9,12) anlamlı farklılık tespit edildi $(p<0.05)$.

\begin{tabular}{|c|c|c|c|}
\hline \multicolumn{3}{|c|}{ Tablo 1. Yıllara göre HPV pozitifliği ve tiplere göre dağılımı } \\
\hline HPV TiP & $\begin{array}{c}2018 \\
(n)\end{array}$ & $\begin{array}{c}2019 \\
(n)\end{array}$ & $\begin{array}{c}\text { TOPLAM } \\
\%(n)\end{array}$ \\
\hline 16 & 32 & 59 & $27(n=91)$ \\
\hline 31 & 15 & 30 & $13,4(n=45)$ \\
\hline 51 & 19 & 24 & $12,8(n=43)$ \\
\hline 52 & 10 & 33 & $12,8(n=43$ \\
\hline 39 & 4 & 29 & $9,79(n=33)$ \\
\hline 56 & 8 & 24 & $9,50(n=32)$ \\
\hline 68 & 8 & 22 & $8,9 \quad(n=30)$ \\
\hline 58 & 8 & 15 & $6,83(n=23)$ \\
\hline 59 & 1 & 19 & $5,93(n=20)$ \\
\hline 35 & 6 & 13 & $5,64(n=19)$ \\
\hline 18 & 7 & 8 & $4,45(n=15)$ \\
\hline 33 & 1 & 12 & $3,86(n=13)$ \\
\hline 45 & 4 & 8 & $3,56(n=12)$ \\
\hline DiĞER & 32 & 65 & $28,7(n=97)$ \\
\hline Toplam & 155 & 361 & 516 \\
\hline
\end{tabular}

Tablo 2. HPV pozitif olgularda HPV tipleri ve bu olgulardaki servikal smear dağılımı

\begin{tabular}{|c|c|c|c|c|c|c|}
\hline HPV & $\begin{array}{c}\text { Normal } \\
(n)\end{array}$ & $\begin{array}{c}\text { Enfeksiyon } \\
(n)\end{array}$ & $\begin{array}{c}\text { ASC-US } \\
(n)\end{array}$ & $\begin{array}{c}\text { LGSIL } \\
(\mathrm{n})\end{array}$ & $\begin{array}{c}\text { AGC } \\
(\mathrm{n})\end{array}$ & $\begin{array}{c}\text { Yetersiz } \\
(\mathrm{n})\end{array}$ \\
\hline 16 & 27 & 3 & 3 & - & - & 8 \\
\hline 18 & 2 & - & - & - & - & 1 \\
\hline 31 & 11 & 4 & - & - & - & 5 \\
\hline 33 & 3 & 1 & - & - & - & 1 \\
\hline 35 & 4 & 2 & 1 & - & - & 2 \\
\hline 39 & 6 & - & - & - & - & 2 \\
\hline 45 & 4 & 1 & - & - & - & - \\
\hline 51 & 9 & - & 1 & - & - & 3 \\
\hline 52 & 6 & 6 & 2 & - & - & 3 \\
\hline 56 & 7 & 1 & 1 & 1 & - & 3 \\
\hline 58 & 5 & 5 & - & - & - & 1 \\
\hline 59 & 3 & - & - & - & - & 1 \\
\hline Mikst & 96 & 42 & 11 & 7 & 1 & 31 \\
\hline Toplam & 183 & 65 & 19 & 8 & 1 & 61 \\
\hline
\end{tabular}




\begin{tabular}{|c|c|c|c|c|c|}
\hline & HPV & Normal & Bazal HH & CIN I & CIN II-III \\
\hline \multirow{13}{*}{ Sigara (+) } & Mikst & 2 & 30 & 4 & 0 \\
\hline & 16 & 0 & 10 & 0 & 0 \\
\hline & 18 & 0 & 0 & 0 & 0 \\
\hline & 31 & 1 & 6 & 1 & 0 \\
\hline & 33 & 0 & 1 & 0 & 0 \\
\hline & 35 & 0 & 4 & 1 & 0 \\
\hline & 39 & 0 & 2 & 0 & 0 \\
\hline & 45 & 0 & 1 & 0 & 0 \\
\hline & 51 & 1 & 2 & 0 & 0 \\
\hline & 52 & 1 & 4 & 0 & 0 \\
\hline & 56 & 0 & 3 & 1 & 0 \\
\hline & 58 & 0 & 2 & 0 & 0 \\
\hline & 59 & 0 & 0 & 0 & 0 \\
\hline \multirow{13}{*}{ Sigara (-) } & Mikst & 16 & 126 & 6 & 4 \\
\hline & 16 & 3 & 26 & 2 & 0 \\
\hline & 18 & 0 & 3 & 0 & 0 \\
\hline & 31 & 0 & 11 & 1 & 0 \\
\hline & 33 & 0 & 4 & 0 & 0 \\
\hline & 35 & 0 & 3 & 1 & 0 \\
\hline & 39 & 1 & 5 & 0 & 0 \\
\hline & 45 & 1 & 3 & 0 & 0 \\
\hline & 51 & 0 & 10 & 0 & 0 \\
\hline & 52 & 1 & 10 & 1 & 0 \\
\hline & 56 & 2 & 7 & 0 & 0 \\
\hline & 58 & 0 & 9 & 0 & 0 \\
\hline & 59 & 1 & 3 & 0 & 0 \\
\hline
\end{tabular}

*Sigara içip içmemeye göre HPV pozitifliği açısından gruplar arasında anlamlı fark mevcuttur (\%5,96 vs. \%9,12; $p<0.05)$.

\section{Tartışma}

HPV kanser yapma özelliğine göre yüksek riskli (HR-HPV), olası yüksek riskli (PR-HPV) ve düşük riskli (LR-HPV) olarak üç gruba ayrılır (7). Servikal kanserlerin \%70'inden HPV 16 ve HPV 18 sorumludur (8). Kanser için yüksek riskli olan tipler 16, 18, 31, 33, 35, 35, 39, $45,51,52,56,58,68,73,82$ 'dir (9). Servikal lezyonları erken tanı ile kansere dönüşmeden tespit edebiliriz. Bu nedenle taramanın ilk basamağını serviksin prekanseröz intraepitelyal lezyonlarının erkenden tespit edilmesi oluşturur (10).

Günümüzde en kabul gören tarama yöntemi olan servikal smear ve HPV DNA testinin aynı örnekte çalışılmasının (co-test) daha duyarlı olduğu bildirilmiştir. (11). Amerika Kolposkopi ve Servikal Patolojiler Derneği (ASCCP) ve Amerika Obstetrisyen ve Jinekologlar Derneği (ACOG), 30-65 yaş aralığındaki kadınların co-test ile beş yılda bir taranmasını önermektedir $(12,13)$. Türkiye'nin de son yıllarda PAP smear ve HPV DNA değerlendirmesi ile tüm toplumun taranması için ciddi bir çalışması olmuştur. Sağlık Bakanlığı 30-65 yaş arası kadınlarda 5 yılda bir PAP smear ve HPV DNA taraması önermektedir (14) ve tüm bu hizmetleri ücretsiz sağlamaktadır. Hastanemiz bölgemizin kanser ileri araştırma merkezi konumundadır. Bu bilgilerin ışığı altında biz de hastanemizde şüpheli servikal lezyon nedeni ile değerlendirilen olguların HPV prevalansını ve yönetimini araştırmayı amaçladık.

Son 15 yılda, dünya çapında servikal HPV DNA'sının tanımlanmasına ilişkin epidemiyolojik veriler üretmek için büyük çabalar sarf edilmiştir. 59 ülkeden 194 çalışmayı birleştiren ve servikal HPV enfeksiyonu için PCR teknikleri ve normal sitolojik bulguları olan 1.016.719 kadını kapsayan bir meta-analiz yayınlanmıştır. Çalışma sonuçlarına göre; normal servikal sitolojik bulguları olan kadınların \%11,7'sinin servikal HPV enfeksiyonuna sahip olduğu, ülkelere özgü HPV prevalanslarının \%1,6 ile \%41,9 arasında değiştiği ve servikal HPV enfeksiyonunun yaş dağılımında bölgelerin yarısında genç yaşlarda ilk zirve (cinsel başlangıçtan hemen sonra), orta yaşlarda daha düşük yaygınlık platosu ve ileri yaşlarda (>45 yaş) ise azalma olduğu bildirilmiştir (15).

Çalışma sonuçlarımıza göre bölgemizde HPV prevalansı \%5,45 ( $n=337 / 6186$ ) olarak saptandı. Yıllara göre dağılımda pozitiflik açısından bir fark tespit edilmedi. Türkiye'de HPV pozitiflik prevalansı ile ilgili çalışmalarda bölgelere göre Eskişehir'de 1081 olgunun dahil edildiği bir çalışmada, HPV prevalansı \%3 olarak bulunmuş ve olguların \%68,8'i yüksek risk HPV, \%28,1'i ise düşük risk HPV olarak bildirilmiştir. Olası risk faktörleri arasında ise doğum sayısının fazla olması, oral kontraseptif (OKS) yöntemi ile korunmak ve sigara içmenin olduğu sıralanmıştır (16). Bölgemizdeki HPV prevalansı ise \%5.45 ile daha yüksek bulunmuştur (vs \%3). Çorum'da yapılan bir başka HPV tiplendirme çalışmasında toplam 33649 hastanın 1108 'inde HPV pozitifliği saptanmıştır (\%3.29) ve en sık görülen tip olarak HPV $16(\% 14,69)$ rapor edilmiştir. Pozitif HPV tarama testi olan 1108 olgunun servikal sitoloji sonuçlarında, \%25,18 sitoloji normal tespit edilirken, $\% 41,34$ olguda ise enfeksiyon raporlanmıştır (17). HPV pozitif olanların \%6,32'sinin sitoloji sonucu ASC-US, \%0,45'nin ise AGC olarak bildirilmiştir. LSIL sıklığı $\% 8,21$, HGSIL \%0,63 olguda bildirilmiştir. Van merkezli Şahin HG ve ark.'nın 2017 yılında yaptığı çalışmada, yüksek riskli HPV tiplerinin oranını \%2,8, anormal sitoloji oranını ise \%12,9 olarak bildirilmiştir. Ayrıca anormal sitoloji oranlarında, servikal kancer: 0,1\%, LGSIL: \%1,6, HGSIL: \%0,5, ASC-H: 2,1\%, AGC: \%0,4 ve ASCUS: 8,3 olarak rapor edilmiştir (18). Konya merkezli Fındık S ve ark.'nın çalışmasında ise HPV pozitiflik oranı \%3,16 olarak tespit 
edilmiş ve servikal sitoloji \%63,61'inde normal, \%6,6'sında ASCUS, \%0,73'ünde ASC-H, \%10'unda LGSIL, \%0,53'ünde HGSIL ve AGC, \%0,03'ünde andenokarsinoma in sutu olarak bildirilmiştir (19). Bizim çalışmamızda ki HPV pozitif vakalardan alınan smear örneklerinin analizinde, normal \%54,3, enfeksiyon \%19,28, ASCUS \%5,63, LGSIL \%2,37, AGC \%0,29 oranlarında tespit edilmiştir. HGSIL (yüksek dereceli skuamöz intraepitelyal lezyon) ve AIS (adenokarinoma in sutu) ve ASC-H (Atipical Squamous CellsCannot Exclude High Grade Squamous Intraepithelial Lesions) tespit edilmemiştir. HPV ve sitoloji birlikteliği açısından çalışma sonuçlarımızla ulusal literatür oranları genel olarak benzerdir.

Türk Onkoloji Derneği'nin çok merkezli bir çalışmasında HPV prevalansı \%25 oranında bildirilmiştir. Anormal sitoloji olan olgularda HPV pozitiflik oranı \%57, normal sitoloji olanlarda ise \%27 olarak tespit edilmiştir. En sık görülen HPV tipleri olarak HPV 16 \%31, HPV 18 \%, HPV 31 \%6, HPV 51 \%5 şeklinde bildirilmiştir (20). HPV prevalans oranının bizim çalışmaya kıyasla yüksek bulunmasının $(\% 25$ vs $\% 5,45)$ nedeninin çalışma gruplarında yüksek riskli olguların değerlendirilmesinden kaynaklandığını düşünüyoruz. Bizim çalışma grubumuz normal risk grubundaki hastalardan oluşmakta idi ve çalışmamızda en sık HPV 16 (\%27), HPV 31 (\%13,3), HPV 51 (\%12,7) ve HPV $52(\% 12,7)$ tipleri belirlenmiştir. HPV 18 'in literatüre göre az oranda saptanmasının $(\% 4,45)$ mikst tiplerin içinde sıklıkla raporlanmasından kaynaklandığını düşünmekteyiz. Kitimizin sınıflandıramadığı diğer grup HPV tipleri \%28,7 oranında rapor edildi. Bunun yanında \%55,8 vakada iki ya da daha fazla tip izole edildi. En sık birliktelik gösteren tipler HPV 16 ve HPV 68 idi.

Çalışmamızda, kolposkopik biyopsi sonuçları \%49,6 CIN 1, \%7,4 CIN2-3, \%1,2 skuamöz hücreli karsinom olarak tespit edildi. Kolposkopik biyopsi sonucu CIN 1-2-3 görülen en sık HPV tipleri 16/31/35/52/56 idi. Preinvaziv ve invaziv lezyonların incelendiği bir çalışmada kolposkopik biyopsi sonuçları; CIN I (\%26,2), CIN II $(\% 1,6)$, CIN III $(\% 6,6)$, karsinoma in situ (CIS) (\%1,6), CIN I-II $(\% 8,2)$, CIN II-III $(\% 13,1)$ olarak raporlanmıştır. Örneklerde en sık HPV 16, HPV 53 tespit edilmiştir (21).

Sigara içenlerde serviks kanserinin daha fazla görüldüğü bilinmektedir (9). Çalışmamızda sigara içenlerde en sık görülen HPV tipleri 16/31/35/52 iken içmeyenlerde 16/31/52/51 idi. Bizim çalışmamızda da literatür ile uyumlu olarak sigara içenlerde HPV pozitifliği oranı sigara içmeyenlere göre anlamlı derecede yüksek bulunmuştur (\%5,96 vs \%9,12).

Çalışmamız bölgesel olarak konu ile ilgili yapılmış ilk çalışmadır.
Ancak bunun yanında limitasyonları da göz ardı edilmemelidir. Birinci ve en önemli limitasyonumuz çalışmamızın retrospektif dizaynıdır. Diğer bir taraftan çalışmamızda kullanılan HPV kitinin tüm HPV tiplerine duyarlı olmaması ve düşük riskli HPV tiplerinin çalışmamızda taranmaması yine önemli bir limitasyonumuzdur. Çalışmamız prospektif dizaynlı, büyük ölçekli, daha çok HPV tiplerine duyarlı kitlerin kullanıldığı çalışmalarla desteklenmelidir.

Çalışmamı sonuçları dahilinde cinsel olarak aktif kadınlarda servikalkansertaramasınınönemibirkere dahaortaya konmuştur. 30 yaş üzerinde HPV DNA ve servikal smear kombinasyonu ile yapılan serviks kanseri tarama programlarına katılmanın önemi akılda tutulmalıdır. Çalışmamız Doğu Karadeniz Bölgesi'nin HPV prevalansını kesitsel olarak göstermesi açısından bir ilktir.

Çıkar çatışması: Bu yazı tamamen bilimsel amaçla yazıımış olup, yazarların bu yazı ile ilgili herhangi bir çıkar çatışması bulunmamaktadır.

\section{Kaynaklar}

1. Satterwhite $\mathrm{CL}$, Torrone $\mathrm{E}$, Meites E, Dunne EF, Mahajan R, Ocfemia MC, Su J, Xu F, Weinstock H. 2013. Sexually transmitted infections among US women and men: prevalence and incidence estimates, 2008 Sex Transm Dis 2013; 40:187-193.

2. Dunne EF, Park IU. HPV and HPV-associated diseases. Infect Dis Clin North Am 2013; 27:765-778.

3. Bray F, Ferlay J, Soerjomataram I, Siegel RL, Torre LA, Jemal A. (2018) Global cancer statistics 2018: GLOBOCAN estimates of incidence and mortality worldwide for 36 cancers in 185 countries. CA Cancer J Clin 2018; 68:394-424.

4. Gong P, Wang Z, Geng J, Tan X. Comparative Study on Detection and Typing of Human Papillomavirus (HPV) Infection with Microarray Using Paraffin-Embedded Specimens from Squamous Cell Carcinoma and Cervical Precursor Lesions. J Nanosci Nanotechnol 2017; 17:990-997.

5. Kaleli I, Aksoy L, Demir M, et al. Prevalence and Genotype Distribution of Human Papillomavirus in Patients Attending to Gynecology Polyclinics Mikrobiyol Bul 2019; 53:170-178.

6. Hasbek M, Çelik C, Çabuk A, Bakıcı MZ. Sivas Bölgesinde Servikal Örneklerde Human papillomavirus Sıklığı ve Genotip Dağılımı. Türk Mikrobiyol Cem Derg 2018; 48:199-204.

7. Schiffman $M$, Herrero $R$, Desalle $R$, et al. The carcinogenicity of human papillomavirus types reflects viral evolution. Virology 2005; 337:76-84. 
8. Baseman JG, Koutsky LA. The epidemiology of human papillomavirus infections. J Clin Virol 2005; 32:16-24.

9. Dehn D, Torkko KC, Shroyer KR. Human papillomavirus testing and molecular markers of cervical dysplasia and carcinoma. Cancer 2007; 111:1-12.

10. Mavi Aydoğdu SG, Özsoy Ü. Cervical cancer and HPV. Androl Bul $2018 ; 20: 25-29$.

11. Yıldırım D. Gökaslan H. Serviks kanseri taramasında HPV DNA testinin yeri. Türk Jinekolojik Onkoloji Dergisi 2015; 1:1-6.

12. Saslow D, Solomon D, Lawson HW, et al. American Cancer Society, American Society for Colposcopy and Cervical Pathology, and American Society for Clinical Pathology screening guidelines for the prevention and early detection of cervical cancer. Am J Clin Pathol 2012; 137:516-542.

13. Committee on Practice Bulletins-Gynecology. ACOG Practice Bulletin Number 131: Screening for cervical cancer. Obstet Gynecol 2012; 120:1222-1238.

14. Sağlık Bakanlığı, Halk Sağlığı Genel Müdürlüğü (2020), HPV Tarama Testi https://hpvtarama.saglik.gov.tr/duyurular/Sayfa/ HpvTaramaTestiNasilYapilir [Erişim tarihi: 24.09.2020].

15. Bruni L, Diaz M, Castellsagué X, Ferrer E, Bosch FX, de Sanjosé S. Cervical human papillomavirus prevalence in 5 continents: metaanalysis of 1 million women with normal cytological findings. J Infect Dis 2010; 202:1789-1799.
16. Aslan FG, Us T, Kaşifoğlu N, et al. The positivity for human papillomavirus (hpv) dna and evaluation of probable risk factors among women in Eskişehir region. Taf Prev Med Bull 2015;14:222-228.

17. Kan Ö, Görkem Ü, Barış A, Koçak Ö, Toğrul C, Yıldırım E. Evaluation of the frequency of human papillomavirus (HPV) in women admitted to cancer early diagnosis and screening training centers (KETEM) and analysis of HPV genotypes. Turk Hij Den Biyol Derg 2019; 76:163-168.

18. Sahin HG, Kolusari A, Guducuoglu H. Prevalence of high risk human papillomavirus (HPV) infection and abnormal cervical cytology and knowledge about HPV vaccine in Eastern Turkey. Eur J Gynaecol Oncol 2017; 38:241-244.

19. Findik S, Findik S, Abuoğlu S, Cihan FG, Ilter H, lyisoy MS. Human papillomavirus (HPV) subtypes and their relationships with cervical smear results in cervical cancer screening: a communitybased study from the central Anatolia region of Turkey. Int J Clin Exp Pathol 2019; 12:1391-1398.

20. Dursun P, Ayhan A, Mutlu L, et al. HPV Types in Turkey: Multicenter Hospital Based Evaluation of 6388 Patients in Turkish Gynecologic Oncology Group Centers. Turk Patoloji Derg 2013; 29:210-216.

21. Demirel EE, Şahin HÖ, Preinvaziv ve invaziv servikal lezyonlarda Human Papillomavirus (HPV) tiplerinin prevalansının saptanması. Balıkesir Med J 2018; 2:185-179. 